\title{
Quantitative Trait Loci Conditioning Resistance to Phaeosphaeria Leaf Spot of Maize Caused by Phaeosphaeria maydis
}

\author{
M. L. Carson, USDA-ARS, Cereal Disease Laboratory, St. Paul, MN 55108; and C. W. Stuber and M. L. Senior, \\ USDA-ARS, Plant Science Research Unit, Raleigh, NC 27695
}

\begin{abstract}
Carson, M. L., Stuber, C. W., and Senior, M. L. 2005. Quantitative trait loci conditioning resistance to Phaeosphaeria leaf spot of maize caused by Phaeosphaeria maydis. Plant Dis. 89:571574.

Phaeosphaeria leaf spot (PLS) is a potentially important disease of maize (Zea mays) that has appeared in winter breeding nurseries in southern Florida. Inbred lines related to B73 are particularly susceptible to Phaeosphaeria leaf spot, whereas inbreds related to Mo17 are highly resistant. A previous study of the inheritance of resistance to Phaeosphaeria leaf spot in the cross B73 $\times$ Mo17 found that resistance is highly heritable and controlled by mostly additive gene action at three or four loci. In this study, we used 158 recombinant inbred (RI) lines derived from the cross B73 $\times$ Mo17 to map quantitative trait loci (QTL) governing resistance. The RI lines along with the parent inbred lines and the $F_{1}$ were evaluated for PLS resistance in replicated trials over two winter growing seasons in southern Florida. Using the composite interval mapping (CIM) function of PLABQTL software, five QTL on four different chromosomes were found to control PLS resistance in Mo17. In addition, the additive $\times$ additive interaction between two of these QTL was found to be significant. Our results are in close agreement with the previous study, where generation mean analysis was used to study the inheritance of resistance to PLS.
\end{abstract}

Phaeosphaeria leaf spot (PLS) is caused by the ascomycete Phaeosphaeria maydis (Henn.) Rane, Payak, \& Renfro (anamorph = Phoma maydis, synonym = Leptosphaeria zea-maydis Saccas; Metasphaeria maydis (Henn.) Höhnel), and is a potentially serious foliar disease of maize (Zea mays) that is widely distributed in Central and South America, Asia, and Africa $(5,14)$. PLS is most prevalent in areas of high rainfall and moderate temperatures, such as occur at higher elevations in the tropics. It is becoming an increasingly important disease of maize in South Africa and Brazil. PLS has occurred regularly in southern Florida winter maize breeding nurseries since at least 1990, but it has yet to appear in the rest of the continental United States (6). The ability of PLS to

Corresponding author: M. L. Carson

E-mail: mcarson@umn.edu

Current address for C. W. Stuber: Department of Genetics, North Carolina State University, Raleigh 27695-7614.

Current address for M. L. Senior: Syngenta Biotechnology Inc., Research Triangle Park, NC 27709.

Accepted for publication 19 January 2005.

DOI: 10.1094/PD-89-0571

This article is in the public domain and not copyrightable. It may be freely reprinted with customary crediting of the source. The American Phytopathological Society, 2005. cause damage to maize in other areas of the world makes the introduction of the disease to the United States a potential concern. Initial observations and later replicated inoculated trials of PLS in southern Florida nurseries indicated that the inbred line B73 and its derivatives were particularly susceptible (4,6). Not all B73-derived lines were as susceptible as B73, and some unrelated lines were also found to be quite susceptible to PLS (4). Only a few commercial hybrids were as severely infected as the susceptible hybrid check, indicating that U.S. maize production is not particularly vulnerable to damage from PLS. The susceptibility of several inbred lines widely used as female (seed) parents of commercial hybrids makes this disease a potential concern to the seed industry should it become established in areas of hybrid seed production.

Based on generation mean analysis of segregating populations derived from the cross B73 $\times$ Mo17, resistance to PLS in the inbred line Mo17 appears to be incompletely dominant, highly heritable, and controlled by three to four genes (5). The USDA-ARS maize quantitative genetics program at Raleigh, NC, has developed a number of mapping populations of maize to study the inheritance and manipulation of quantitative trait loci (QTL) for agronomic traits, particularly grain yield. One population, a set of random, recombinant inbred (RI) lines derived from the cross of the agronomically important inbred lines B73 and Mo17, is also suitable for map- ping QTL conditioning partial resistance to a number of diseases (7). B73 is susceptible to many foliar pathogens, whereas Mo17 has a reasonably high level of partial resistance. This study was undertaken to identify and map QTL controlling resistance to PLS in RI lines of maize derived from the cross B73 $\times$ Mo17.

\section{MATERIALS AND METHODS}

Plant materials. A total of 158 random, recombinant $\mathrm{F}_{2: 7}$ inbred lines, derived from the cross of maize inbred lines B73 and Mo17, were produced by successive generations of self-pollination with no selection for agronomic traits. This RI population was initially created by the second author in the late 1980s to map QTL for agronomic traits in germ plasm that is representative of that used in many commercial maize hybrids.

Field trials. The RI lines were evaluated for partial resistance to Phaeosphaeria leaf spot in field trials at Homestead, FL, in the winters of 1994-95 and 1995-96. Plots were planted in early October each year. The experiments consisted of randomized complete blocks with two replications. Individual plots were rows $3.1 \mathrm{~m}$ long, spaced $0.9 \mathrm{~m}$ apart, and planted with 20 seeds each. Seedlings were not thinned, so the final number of plants per row varied. Plots of the parent inbred lines and the $F_{1}$ were included. Plots were not inoculated but relied on natural infection. Plots of PLS-susceptible genotypes in this and neighboring nurseries were uniformly infected. Whole plots were visually rated when the inbred line B73 was at the middent growth stage. A 10 class rating system, where $0=$ no symptoms, $1 \cong 1 \%, 2 \cong$ $3 \%, 3 \cong 5 \%, 4 \cong 10 \%, 5 \cong 25 \%, 6 \cong 50 \%$, $7 \cong 75 \%, 8 \cong 90 \%$, and $9=100 \%$ leaf area spotted, described previously $(4,5)$, was used.

Molecular markers. The RI lines were fingerprinted at 234 restriction fragment length polymorphism (RFLP), isozyme, and Simple Sequence Repeat (SSR) marker loci $(16,17)$ covering $1,683 \mathrm{cM}$ of the maize genome, with an average interval length of $7.5 \mathrm{cM}$, with over $99 \%$ of the genome within $20 \mathrm{cM}$ of the nearest marker. A map was generated using Mapmaker (12) software. The map generated for the B73/Mo17 RI population is available at the Maize Genetics and Genomics Database website. Five percent of marker data was missing from the data set. Marker 
loci were heterozygous at less than $0.4 \%$ tions.

Statistical analyses. Disease severity data were initially analyzed using analysis of variance. Estimates of genotypic $\left(\sigma_{g}^{2}\right)$, error $\left(\sigma^{2}\right)$, and genotype $\times$ environment $\left(\sigma_{\text {gxe }}^{2}\right)$ variance components were calculated from the ANOVA and used to calculate heritabilities on an entry mean basis and their standard errors as described by Hallauer and Miranda (10):

$$
h^{2}=\frac{\sigma_{g}^{2}}{\sigma_{g}^{2}+\sigma_{g x e}^{2} / e+\sigma^{2} / r e}
$$

There were highly significant differences among RI lines for reaction to PLS, and replication effects were small, so RI line means from each experiment were used in analysis of marker data. Putative of all the possible RI line/marker combina-

QTL controlling PLS resistance were detected with a composite interval mapping (CIM) approach using PLABQTL software (18). The map was scanned at 2-cM intervals. Cofactor markers were selected using the cov SELECT option with a LOD score $>2.50$ to enter into the model. The data were analyzed over the two environments, and QTL $\times$ environment effects were estimated. Putative QTL were designated by the corresponding chromosome bin in which they were found. Chromosome bins divide the genetic map of the 10 chromosomes of maize into 90 segments of approximately $20 \mathrm{cM}$ between two fixed core markers (9). The segments or bins are designated with the chromosome number followed by a two-digit decimal (e.g., 1.00, $1.01,1.02$, etc). A bin is the interval that includes all loci from the leftmost or top core marker to the next core marker.

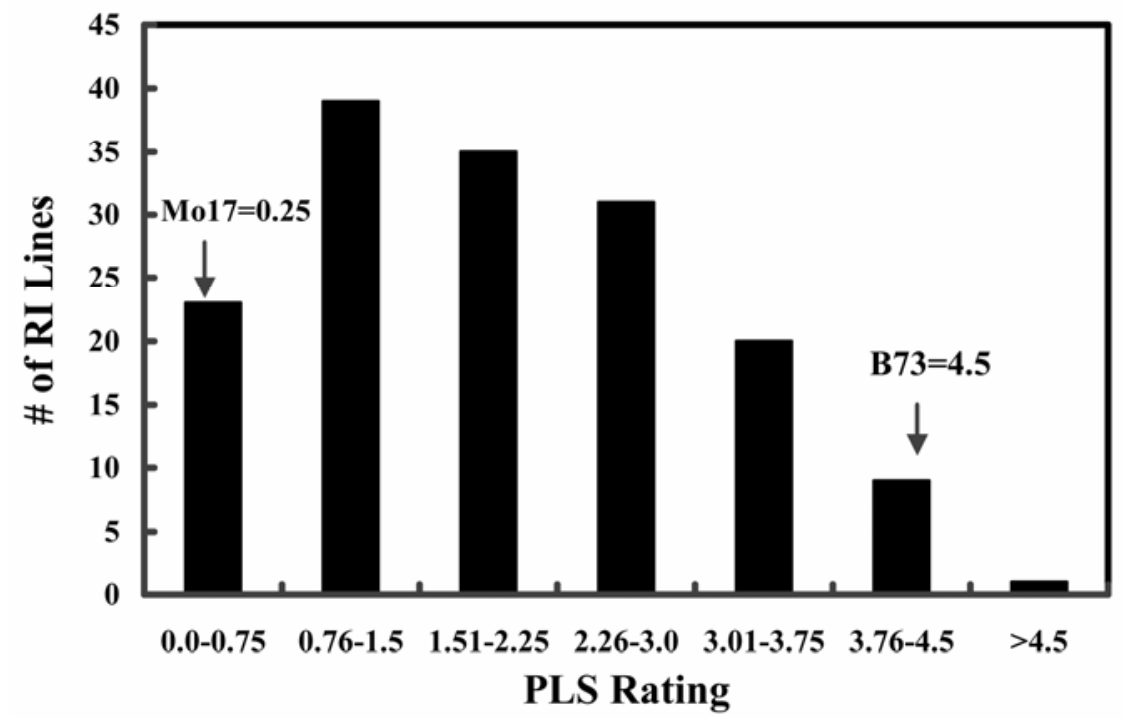

Fig. 1. Frequency distribution of mean Phaeosphaeria leaf spot (PLS) ratings of 158 recombinant inbred (RI) lines derived from the cross of maize inbred lines B73 and Mo17. Ratings are means of two replications in each of two growing seasons in southern Florida.

Table 1. Estimates of variance components and heritability for resistance to Phaeosphaeria leaf spot in 158 recombinant inbred lines of maize from the B73/Mo17 population measured over 2 years

\begin{tabular}{lccc}
\hline \multicolumn{3}{c}{ Variance component } & Heritability \\
\hline$\sigma_{g}^{2}$ & $\sigma_{\text {gxe }}^{2}$ & $\sigma^{2}$ & $0.65 \pm 0.12$ \\
\hline $0.7697 * * a$ & 0.4665 & 0.7256 & \\
\hline a $* *$ indicates variance component is significant at the $P=0.01$ level of probability.
\end{tabular}

Table 2. Analysis of variance for quantitative trait loci (QTL) mapping of Phaeosphaeria leaf spot resistance ( 0 to 9 scale) in the B73/Mo17 recombinant inbred population of maize

\begin{tabular}{lccl}
\hline Source & df & Mean square & $\boldsymbol{F}$ \\
\hline Years & 1 & & \\
Genotypes & 157 & 2.4053 & $2.81^{* * a}$ \\
QTL & 6 & 20.5456 & $9.44^{* *}$ \\
Residuals & 151 & 1.6845 & $1.95^{* *}$ \\
Genotypes $\times$ years & 157 & 0.8546 & 0.83 \\
QTL $\times$ years & 6 & 0.5840 & \\
Residuals $\times$ years & 151 & 0.8653 & \\
Percent genetic variation explained by model: $47.2 \%$ & & \\
\hline
\end{tabular}

a ** indicates mean square is significant at the $P=0.01$ level of probability.
Placement of a locus to a bin is dependent on the precision of mapping.

\section{RESULTS}

Disease development. Phaeosphaeria leaf spot had developed sufficiently by the mid-dent stage in both growing seasons to allow discrimination between the levels of resistance of the two parental inbred lines. B73 and Mo17 had reached PLS ratings of 4.0 and 0.0, respectively, in the 1994-95 season. In the 1995-96 season, B73 and Mo17 had reached PLS ratings of 5.0 and 0.5 , respectively. Differences in PLS ratings of the RI lines were significant and ranged from 0.0 to 5.0 in both seasons. The distribution of mean PLS reactions of RI lines was continuous and somewhat skewed toward increased resistance (Fig. 1). Some RI lines had PLS reactions outside the range of the parental lines, but these PLS reactions did not differ significantly from those of either Mo17 or B73 at their respective ends of the distribution. Narrow sense heritability was estimated to be 0.65 (Table 1), in close agreement with estimates obtained from generation mean analysis in previous studies (5). Genotype $x$ environment interactions were not statistically significant (Table 2).

QTL for resistance to PLS from Mo17 were found on the long arm of chromosome one near the centromere, the long arm of chromosome four, both arms of chromosome seven, and the long arm of chromosome eight (Table 3). Collectively, all the significant QTL effects accounted for 47.3 and $32.6 \%$ of the genotypic and phenotypic variation in PLS severity in the combined analysis, respectively. The QTL on the end of the short arm of chromosome seven in bin 7.01 accounted for the most variation in PLS severity, $11 \%$. QTL on chromosome one in bin 1.06, the QTL on chromosome eight in bin 8.07/8.08, and the other QTL on chromosome seven in bin 7.03 accounted for $9.2,7$, and $6.5 \%$ of the phenotypic variation, respectively. A single QTL on chromosome four in bin 4.07 accounted for $4.1 \%$ of the variation. Significant additive $\times$ additive epistasis (interaction) between the QTL on the end of the short arm of chromosome seven and the QTL on chromosome eight accounting for $4.4 \%$ of the variation in PLS severity was also detected. No significant QTL $\times$ environment interactions were detected (Table 3).

\section{DISCUSSION}

Our results are consistent with a previous study of the inheritance of resistance to Phaeosphaeria leaf spot of maize in the B73 $\times$ Mo17 cross using generation mean analysis (5). Additive gene action is of primary importance, genotype $\times$ environment interactions and epistasis are of minor importance, heritability is high, and three to four loci appear to control resistance. Five QTL on four chromosomes 
were found to control almost half of the genetic variation for PLS resistance in the RI mapping population (Fig. 2). Markers near the QTL on chromosome one include umc133c, umc67, bnl5.59, and umc58. Markers near the QTL on chromosome four include umc66a, npi292, bnl7.65, and umc158. The nearest marker to the QTL on the short arm of chromosome seven is php20581a. Markers near the second QTL on chromosome seven include umc116a, bng1434, phi091, bnl339, and umc110a. Markers near the QTL on chromosome eight include tpi5, npi414a, and umc007. These markers may be appropriate for marker assisted selection (MAS) to improve the level of PLS resistance of maize, develop near-isogenic lines (NIL) containing the QTL, and for further fine mapping of the QTL. Because the location of these putative QTL is not precise or verified, flanking markers that encompass most of the supporting intervals for the QTL should be used. Such flanking markers are available for QTL on chromosome one, chromosome four, chromosome eight, as well as the QTL in chromosome bin 7.03. There is only a single marker suitable for MAS for the QTL on the distal end of chromosome seven. Further markers are needed in this region to more precisely locate the QTL for PLS resistance and for possible MAS.

Our estimate of narrow sense heritability of resistance to PLS among the RI lines (Table 1) is similar to those obtained from $\mathrm{F}_{2}$ and backcross generations from the B73 $\times$ Mo17 cross (5). Because highly homozygous RI lines were used, it was not possible to estimate dominance effects of QTL in this study. However, dominance genetics effects were small in relation to additive genetic effects in the previous study and contributed little to the variation among generation means. The only epistasis estimable using the highly homozygous RI lines was additive $\times$ additive effects. The interaction between the QTL on the end of chromosome seven and the QTL on chromosome eight was highly significant and resulted in an increase in susceptibility.

Genotype $x$ environment interactions are often a feature of many inheritance and QTL mapping studies of disease resistance in maize. Genotype $\times$ environment interaction was of little importance in resistance to Phaeosphaeria leaf spot in this and a previous study (5). QTL $\times$ environment interactions were not statistically significant. The magnitude of the effects of individual QTL were comparable between both years of the study, with the exception of the QTL on chromosome one, whose effect was about twice as great in the 1995-96 season as in the 1994-95 season. In no instance did the direction of a QTL effect change between the two growing seasons of this study. The relatively high heritability and low genotype $\times$ environment interaction observed in this and the previous study indicate that selection for resistance to PLS will be very effective.

Resistance genes to different pests and pathogens are often clustered in the maize genome (13). When QTL identified in this study were compared with previously mapped disease and pest resistance loci, several associations were noticed. The QTL on chromosome one is in the same chromosome bin (1.06) as the Hml locus for resistance to Cochliobolus carbonum R. R. Nelson, race 1 (11). The QTL on chromosome four maps to the same bin as QTL for resistance to Cercospora zeaemaydis Tehon \& Daniels $(3,15)$. The QTL in bin 7.03 on chromosome seven is in the same region that QTL for resistance to Exserohilum turcicum (Pass.) Leonard \& Suggs (8), as well as second brood European corn borer (1) and the sugarcane borer (2), have been found. Despite these associations between reported QTL for resistance to PLS and resistance to other pests and pathogens, we have no direct evidence that these resistances are actually correlated. The inbred line Mo17 is moderately resistant to both $C$. zeae-maydis and E. turcicum, whereas B73 is susceptible. However, both parental inbreds are highly resistant to $C$. carbonum race 1 and are considered susceptible to second brood European corn borer.

The results of this study are likely representative of how Phaeosphaeria leaf spot resistance is inherited in the majority of germ plasm currently used in U.S. maize breeding programs. The two main heterotic groups used in most current U.S. hybrids are largely derivatives of the two parent lines of the RI population, B73 and Mo17.

Table 3. Location and effects of quantitative trait loci (QTL) controlling Phaeosphaeria leaf spot resistance in the B73/Mo17 recombinant inbred mapping population of maize based on composite interval mapping of disease ratings obtained over two winter growing seasons in Homestead, FL

\begin{tabular}{lcccc}
\hline Chromosome bin $^{\mathbf{a}}$ & Nearest marker & $\begin{array}{c}\text { Position of QTL peak } \\
(\mathbf{c M})\end{array}$ & Effect $^{\mathbf{b}}$ & Partial $\boldsymbol{R}^{\mathbf{2}}$ \\
\hline 1.06 & (umc67) & 118 & $-0.301^{* *}$ & 9.2 \\
4.07 & (npi292) & 132 & $-0.216^{*}$ & 4.1 \\
7.01 & (php20581a) & 0 & $-0.334^{* *}$ & 11.0 \\
7.03 & (phi91) & 48 & $-0.250^{* *}$ & 6.5 \\
$8.07 / 8.08$ & (tpi5) & 150 & $-0.261^{* *}$ & 7.0 \\
$7.01 \times 8.07 / 8.08^{\mathrm{d}}$ & & & $0.206^{* *}$ & 4.4 \\
\hline
\end{tabular}

${ }^{a}$ Chromosome bin location of putative QTL on one of the 10 chromosomes of the maize genome. Bins divide the genetic map into 90 segments of approximately $20 \mathrm{cM}$ between two fixed core markers. Segments are designated with the chromosome number followed by a two-digit decimal (e.g., 1.00, $1.01,1.02$, etc). A bin is the interval that includes all loci from the leftmost or top core marker to the next core marker. Placement of a locus to a bin is dependent on the precision of mapping data and increases in certainty as markers increase in number or populations increase.

${ }^{\mathrm{b}}$ Additive genetic effect of the putative QTL.

c *,** indicate genetic effect is significant at the $P=0.05$ and $P=0.01$ level of probability, respectively.

${ }^{\mathrm{d}}$ Additive $\times$ additive epistatic genetic effect between the two QTL loci.

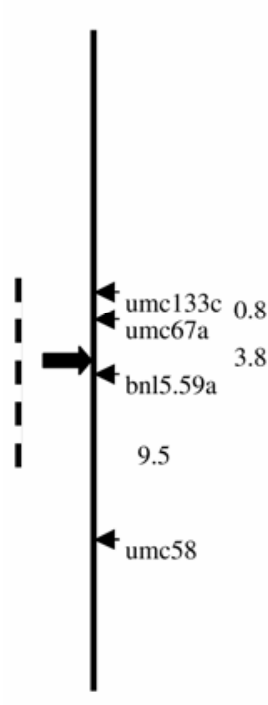

Chromosome one

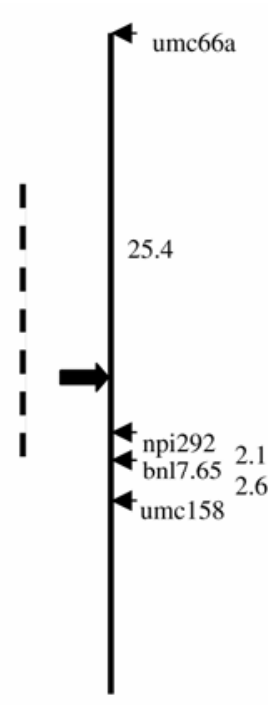

Chromosome four
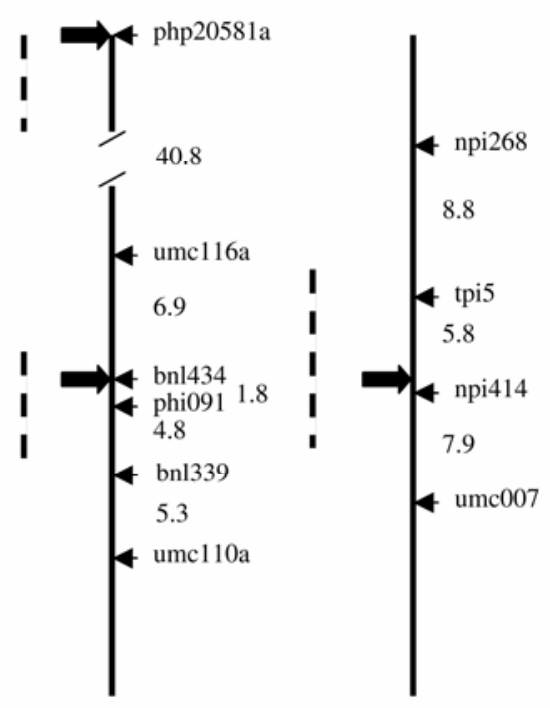

Chromosome seven
Chromosome eight

Fig. 2. Locations of quantitative trait loci (QTL) for resistance to Phaeosphaeria leaf spot of maize (large arrows) and associated markers (small arrows) in the B73/Mo17 recombinant inbred population. Distance (in $\mathrm{cM}$ ) between adjacent markers is to the right of each chromosome; dotted lines to the left indicate supporting intervals for the QTL locations. 
Although most commercial hybrids tested to date are resistant to Phaeosphaeria leaf spot, most inbred lines related to $\mathrm{B} 73$ are quite susceptible (4). These inbred lines are commonly used as female or seed parents in hybrid seed production. Development of Phaeosphaeria leaf spot resistant inbreds of the B73-type should not be particularly difficult given the few genes involved and high heritability observed in this study. Most sources of resistance to Phaeosphaeria leaf spot such as Mo17 belong to the 'Lancaster' heterotic group, possibly complicating the transfer of Phaeosphaeria leaf spot resistance from these sources to B73-type inbreds of the 'Stiff Stalk Synthetic' heterotic group. There is the potential that this transfer of resistance between heterotic groups could disrupt the heterotic pattern for grain yield used in U.S. maize hybrids. Phaeosphaeria leaf spot has not been found outside southern Florida in the United States, and there is no indication that it represents an immediate threat to major maize production areas in the Midwest. The lack of knowledge concerning the epidemiology of this disease means it is difficult to make accurate predictions of the potential for Phaeosphaeria leaf spot to cause widespread damage. An inadvertent shift toward increased susceptibility to Phaeosphaeria leaf spot in the genetic base of U.S. hybrids would place U.S. maize production at an increased risk.

\section{LITERATURE CITED}

1. Beavis, W. D., Smith, O. S., Grant, D., and Fincher, R. 1994. Identification of quantitative trait loci using a small sample of topcrossed and F4 progeny from maize. Crop Sci. 34:882896.

2. Bohn, M., Khairallah, M. M., Gonzalez-deLeon, D., Hoisington, D. A., Utz, H. F., Deutsch, J. A., Jewell, D. C., Mihm, J. A., and Melchinger, A. E. 1996. QTL mapping in tropical maize: Genomic regions affecting leaf feeding resistance to sugarcane borer and other traits. Crop Sci. 36:1352-1361.

3. Bubeck, D. M., Goodman, M. M., Beavis, W. D., and Grant, D. 1993. Quantitative trait loci controlling resistance to gray leaf spot in maize. Crop Sci. 33:838-847.

4. Carson, M. L. 1999. Vulnerability of U.S. maize germ plasm to Phaeosphaeria leaf spot. Plant Dis. 83:462-464.

5. Carson, M. L. 2001. Inheritance of resistance to Phaeosphaeria leaf spot of maize. Plant Dis. 85:798-800.

6. Carson, M. L., Goodman, M. M., and Glawe, D. A. 1991. Phaeosphaeria leaf spot of maize in Florida. Plant Dis. 75:968.

7. Carson, M. L., Stuber, C. W., and Senior, M. L. 1996. Identification of quantitative trait loci (QTLs) for resistance to two foliar diseases in a mapping population of recombinant inbred (RI) lines of maize. (Abstr.) Phytopathology 86:S59.

8. Dingerdissen, A. L., Geiger, H. H., Lee, M., Schechert, A., and Welz, H. G. 1996. Interval mapping of genes for quantitative resistance of maize to Setosphaeria turcica, cause of northern leaf blight, in a tropical environment. Mol. Breed. 2:143-156.

9. Gardiner, J., Coe, E., Jr., Melia-Hancock, S., Hoisington, D., and Chao, S. 1993. Development of a core RFLP map in maize using an immortalized-F2 population. Genetics
134:917-930.

10. Hallauer, A. R., and Miranda, J. B. 1988 Quantitative Genetics in Maize Breeding. 2nd ed. Iowa State University, Ames.

11. Johal, G., and Briggs, S. P. 1992. Reductase activity encoded by the HM1 disease resistance gene in maize. Science 258:985-987.

12. Lander, E. S., Green, P., Abrahamson, J., Barlow, A., Daly, M. J., Lincoln, S. E., and Newburg, L. 1987. Mapmaker: An interactive computer package for constructing primary genetic linkage maps of experimental and natural populations. Genomics 1:174-181.

13. McMullen, M. D., and Simcox, K. D. 1995. Genomic organization of disease and insect resistance genes in maize. Mol. Plant-Microbe Interact. 8:811-815.

14. Rane, M. S., Payak, M. M., and Renfro, B. L. 1966. A Phaeosphaeria leaf spot of maize. Indian Phytopathol. Soc. Bull. 3:8-10.

15. Saghai Maroof, M. A., Yue, Y. G., Xiang, Z. X., Stromberg, E. L., and Rufener, G. K. 1996. Identification of quantitative trait loci controlling resistance to gray leaf spot disease in maize. Theor. Appl. Genet. 93:539-546.

16. Senior, M. L., Chin, E. C. L., Lee, M. Smith, J. S. C., and Stuber, C. W. 1996. Simple sequence repeat markers developed from maize sequences found in the GENBANK database: Map construction. Crop Sci. 36:1676-1683

17. Stuber, C. W., Lincoln, S. E., Wolff, D. W., Helentjaris, T., and Lander, E. S. 1992. Identification of genetic factors contributing to heterosis in a hybrid from two elite maize inbred lines using molecular markers. Genetics 132:823-839

18. Utz, H. F., and Melchinger, A. E. 1996. PLABQTL: A program for composite interval mapping of QTL. J. Quant. Trait Loci. Crop Science Society of America. Online publication: vol. 2, paper 1 